\title{
ANALISIS FAKTOR-FAKTOR YANG MEMPENGARUHI KEINGINAN DAN KEPUTUSAN BERKUNJUNG KE PANTAI SERTA IMPLIKASINYA TERHADAP WILLINGNESS TO RECOMMENDATION (Studi Empiris pada Pengunjung Pantai Teluk Asmara di Kabupaten Malang Jawa Timur)
}

\author{
Nanik Wahyuningtiyas \\ Dosen Fakultas Ekonomi \& Bisnis \\ Email:cutekinan@gmail.com
}

\begin{abstract}
Abstrak
Tujuan penelitian ini adalah: 1) Untuk mengetahui dan menganalisis pengaruh daya tarik, branding, image, wom, e-wom, fasilitas dan pelayanan secara parsial terhadap keinginan berkunjung ke Pantai Teluk Asmara, 2) Untuk mengetahui dan menganalisis pengaruh daya tarik, branding, image, wom, e-wom, fasilitas dan pelayanan secara simultan terhadap keinginan berkunjung ke Pantai Teluk Asmara, 3) Untuk mengetahui dan menganalisis pengaruh daya tarik, branding, image, wom, e-wom, fasilitas dan pelayanan secara parsial terhadap keputusan berkunjung ke Pantai Teluk Asmara, 4) Untuk mengetahui dan menganalisis pengaruh daya tarik, branding, image, wom, e-wom, fasilitas dan pelayanan secara simultan terhadap keputusan berkunjung ke Pantai Teluk Asmara, 5) Untuk mengetahui dan menganalisis pengaruh keinginan berkunjung dan keputusan berkunjung ke Pantai Teluk Asmara, 6) Untuk mengetahui dan menganalisis pengaruh daya tarik, branding, image, wom, e-wom, fasilitas dan pelayanan secara parsial terhadap willingnes to recommendation di Pantai Teluk Asmara, 7) Untuk mengetahui dan menganalisis pengaruh daya tarik, branding, image, wom, e-wom, fasilitas dan pelayanan secara simultan terhadap willingnes to recommendation di Pantai Teluk Asmara 8) Untuk mengetahui dan menganalisis pengaruh keinginan berkunjung terhadap willingness to recommendation di Pantai Teluk Asmara, 9) Untuk mengetahui dan menganalisis pengaruh keputusan berkunjung terhadap willingness to recommendation di Pantai Teluk Asmara.

Sampel yang digunakan dalam penelitian ini adalah pengunjung yang dijumpai di Pantai Teluk Asmara dengan cara membagikan kuisioner, maka hasil penelitian menunjukkan bahwa secara umum faktor-faktor tersebut perpengaruh terhadap keinginan ,keputusan berkunjung, dan willingness to recommendation di Pantai Teluk Asmara. Dalam penelitian ini juga dapat diketahui jika keinginan dan keputusan berkunjung sebagi variabel intervening tidak berdampak pada willingness to recommendation di Pantai Teluk Asmara.

Kata kunci : daya tarik, branding, image, wom, e-wom, fasilitas, pelayanan, keinginan berkunjung, keputusan berkunjung, willingness to recommendation.
\end{abstract}

\footnotetext{
Abstract

The purpose of this research are: 1) To know and analyze the influence of attractiveness, branding, image, wom, e-wom, facilities and services partially to the desire to visit the Teluk Asmara Beach, 2) To know and analyze the influence of attractiveness, branding, image, wom, e-wom, facilities and services simultaneously to the desire to visit the Teluk Asmara Beach, 3) To know and analyze the influence of attractiveness, branding, image, wom, e-wom, facilities and services partially to the decision to visit the Teluk Asmara Beach, 4) To know
} 
and analyze the influence of attraction, branding, image, wom, e-wom, facilities and services simultaneously to the decision to visit the Teluk Asmara Beach, 5) To know and analyze the influence of visiting desire and decision to visit the Teluk Asmara Beach, 6) To know and analyze the influence of attractiveness, branding, image, wom, e-wom, facilities and services partially limited ap willingnes to recommendation at Teluk Asmara Beach, 7) To know and analyze the effect of attraction, branding, image, wom, e-wom, facilities and services simultaneously to the willingness to recommendation at Teluk Asmara Beach 8) To know and analyze the influence of desire visit to the willingness to recommendation at Teluk Asmara Beach, 9) To know and analyze the influence of visiting decision on willingness to recommendation at Teluk Asmara Beach.

The samples used in this study were the visitors found in the Teluk Asmara Beach by distributing questionnaires, the result of the research showed that in general the factors influenced the desire, the visiting decision, and the willingness to recommendation in Teluk Asmara Beach. In this study can also be known if the desire and decision to visit as an intervening variable does not affect the willingness to recommendation in Teluk Asmara Beach.

Keyword : attractiveness, branding, image, wom, e-wom, facility, service, visiting desire, visiting decision, willingness to recommendation.

\section{PENDAHULUAN}

Indonesia merupakan salah satu negara kepulauan yang memiliki kekayaan alam yang sangat berlimpah. Pemerintah melalui Kementrian Pariwisata menetapkan target pariwisata nasional pada tahun 2019 sebanyak 20 juta wisatawan mancanegara. Sedangkan untuk wisatawan nusantara sebanyak 275 juta wisatawan. Kontribusi pariwisata terhadap Produk Domestik Bruto (PDB) sebesar 15\%. Selain itu, pada tahun 2019 daya saing pariwisata ditargetkan berada pada ranking 30 dunia, naik dua puluh peringkat dari posisi saat ini yang berada pada rangking 50 dunia (wikipedia 2017).

Di era yang semakin modern seperti sekarang ini, perkembangan teknologi dan ilmu pengetahuan semakin mengalami kemajuan yang cukup pesat. Berbagai alat canggih diciptakan untuk membantu dan mempermudah segala kegiatan. Hal ini mengakibatkan manusia terlalu asik dengan rutinitasnya sendiri. Hampir setiap hari mereka melakukan berbagai kegiatan yang tidak ada hentinya sehingga menjadi sangat membosankan dan menjenuhkan.

Malang merupakan sebuah kabupaten/ kota di Jawa Timur yang memiliki pesona dan panorama alam yang menakjubkan. Malang memiliki banyak sekali objek wisata yang menakjubkan mulai dari situs budaya, situs bersejarah, spot foto kekinian, air terjun yang indah, juga pantai yang berjajar disepanjang garis pantai di Malang selatan. Dengan branding The Heart Of East Java diharapkan mampu untuk mendongkrak kunjungan wisata.

Kabupaten Malang menurut wikipedia memiliki luas wilayah 1.365 mil persegi $(3.534,86 \mathrm{~km} 2)$ dan memiliki garis pantai sepanjang $102,5 \mathrm{~km}$ diambil dari sepanjang pantai selatan Jawa mulai dari pantai Modangan di Donomulyo sampai pantai Licin di Ampelgading. Menurut data Disbudpar obyek wisata pantai di Malang ada 91 sedangkan menurut Kesatuan Pengelola Hutan (KPH) kantor Perhutani terdapat 101 objek wisata pantai. 
Ini merupakan kekayaan alam yang memiliki potensi sangat luar biasa bagi masyarakat dan pemerintah kabupaten Malang.

Pantai Teluk Asmara merupakan salah satu obyek wisata baru dan memiliki daya tarik tersendiri. Pantai ini tergolong baru dikarenakan awal pembukaan secara resmi pada bulan April 2017. Dalam perkembangannya Pantai Teluk Asmara bekerja sama dengan pihak swasta untuk membangun wahana-wahana baru serta pengelolaannya. Sangatlah penting bagi pengelola Pantai Teluk Asmara untuk mengidentifikasi dan menganalisa faktor-faktor yang mempengaruhi wisatawan untuk berkunjung dan melakukan kunjungan ulang sehingga mampu meningkatkan jumlah wisatawan yang datang dari waktu ke waktu. Survei awal dilakukan untuk mendapatkan fenomena yang sesuai dengan kenyataan dilapangan. Hasil dari survei awal yang dilakukan peneliti di lokasi penelitian setelah melakukan wawancara singkat terhadap 10 orang pengunjung di dapat beberapa faktor yang mendasari mereka untuk berkunjung ke Pantai Teluk Asmara.

Suatu perusahaan yang bergerak dalam bidang produksi pada dasarnya ingin produknya terlihat berbeda dengan produk sejenis yang sudah ada. Oleh karenanya perusahaan harus menggali terus apa yang membuat produk tersebut berbeda. Dengan perbedaan produk tersebut diharapkan dapat memunculkan daya tarik suatu produk. Daya tarik produk menurut Tjiptono (1997) adalah segala sesuatu yang dapat ditawarkan, dicari, dibeli, dan dikonsumsi oleh pasar sebagai pemenuhan kebutuhan dan keinginan pasar. Suatu produk tentu mempunyai mutu, mutu ini dipengaruhi oleh beberapa aspek diantaranya daya tarik (attractiveness), daya tahan (maintainability), dan dalam penggunaan (ease of use) dan suatu produk juga harus bisa memuaskan keinginan dari konsumen (Kotler,2000).

\section{KAJIAN TEORI}

Merek dalam suatu perusahan sangat penting untuk memperkuat posisi perusahaan diketatnya persaingan untuk membedakan produk dengan pesaing. American Marketing Association dalam Kotler dan Keller (2016:322) mendefinisikan merek sebagai: "Nama, istilah, tanda, simbol, atau desain, atau kombinasi dari mereka, yang dimaksudkan untuk mengidentifikasi barang atau jasa dari satu penjual atau kelompok penjual dan untuk membedakan mereka dari para pesaing".

Image (citra) menjadi salah satu faktor yang mempengaruhi konsumen dalam keputusan pembelian, baik keputusan sebelum pembelian maupun setelah pembelian. Menurut Kotler dan Keller (2009:629) image (citra) adalah: "Citra adalah seperangkat keyakinan, ide dan kesan yang dimiliki seseorang terhadap suatu objek dimana sikap dan objek tindakan seseorang terhadap suatu objek sangat dikondisikan oleh citra objek tersebut".

Kotler dan Keller (2009) mengemukakan bahwa word of mouth (WOM) atau komunikasi dari mulut ke mulut merupakan proses komunikasi yang berupa perpindahan informasi baik secara individu maupun kelompok terhadap suatu produk atau jasa yang bertujuan untuk memberikan 
informasi secara personal. Komunikasi dari mulut ke mulut merupakan salah satu saluran komunikasi yang sering digunakan oleh perusahaan yang memproduksi baik barang maupun jasa karena komunikasi dan mulut ke mulut (word of mouth) dinilai sangat efektif dalam memperlancar proses pemasaran dan mampu memberikan keuntungan kepada perusahaan.

E-Wom menurut Wardiyastuti (2017) sebagai bentuk komunikasi yang berkembang dari WOM secara elektronik atau dengan penggunaan internet, yang lebih baik dari personal selling atau periklanan konvensional dimana konsumen menggunakan internet untuk membagikan pengalaman setelah menggunakan produk atau jasa, atau konsumen dapat memanfaatkan pengalaman orang lain untuk melakukan pembelian. Keduanya dapat berupa positif aupun negatif, jika saran positif lebih dapat mendorong konsumen lain untuk membuat keputusan pembelian, jika saran negatif lebih memungkinkan konsumen tidak keputusan pembelian.

Keinginan berkunjung atau dengan kata lain minat kunjungan dalam pemasaran lebih dikenal dengan minat beli. Minat beli (willingness tobuy) merupakan bagian dari komponen perilaku dalam sikap mengkonsumsi. Sulistyari (2012:19) menyatakan bahwa minat beli (willingness to buy) didefinisikan sebagai kemungkinan bila pembeli bermaksud untuk membeli produk. Minat beli merupakan perilaku konsumen yang menunjukkan sejauh mana komitmennya untuk melakukan pembelian. Minat beli berbeda dengan niat beli, niat beli adalah suatu tindak lanjut dari minat beli konsumen dimana keyakinan untuk memutuskan akan membeli sudah dalam persentase yang besar. Jadi dapat dikatakan bahwa niat beli adalah tingkatan akhir dalam minat beli berupa keyakinan sebelum keputusan pembelian diambil.

Menurut Kotler (2002), keputusan pembelian adalah tindakan dari konsumen untuk mau membeli atau tidak terhadap produk. Dari berbagai faktor yang mempengaruhi konsumen dalam melakukan pembelian suatu produk atau jasa, biasanya konsumen selalu mempertimbangkan kualitas, harga dan produk sudah yang sudah dikenal oleh masyarakat.

Sebelum konsumen memutuskan untuk membeli, biasanya konsumen melalui beberapa tahap terlebih dahulu yaitu, (1) pengenalan masalah, (2) pencarian informasi, (3) evaluasi alternatif, (4) keputusan membeli atau tidak, (5) perilaku pasca pembelian.

Willingnes to recomendation adalah kesediaan untuk recomendasi seperti yang dinyatakan oleh Wuryandari (2014). Kesediaan recomendasi disini adalah berupa bagian dari perilaku konsumen pasca pembelian.

Berdasarkan kajian literatur yang telah dilakukan sebelumnya, maka hipotesis alternatif penelitianya $(\mathrm{Ha})$ telah dirumuskan peneliti sebagai berikut:

$\mathrm{H1}$ : Bahwa ada pengaruh yang signifikan antara daya tarik (X1), branding (X2), image (X3), wom (X4), e-wom (X5), fasilitas (X6), dan pelayanan (X7) secara parsial terhadap keinginan berkunjung (Y1) ke Pantai Teluk Asmara. H2: Bahwa ada pengaruh daya tarik (X1), branding (X2), image (X3), wom (X4), e-wom (X5), fasilitas (X6), dan pelayanan (X7) secara simultan terhadap keinginan berkunjung (Y1) ke Pantai Teluk Asmara. H3: Bahwa ada pengaruh yang signifikan antara daya tarik (X1), 
branding (X2), image (X3), wom (X4), e-wom (X5), fasilitas (X6), dan pelayanan (X7) secara parsial terhadap keputusan berkunjung (Y2) ke Pantai Teluk Asmara. H4: Bahwa ada pengaruh daya tarik (X1), branding (X2), image (X3), wom (X4), e-wom (X5), fasilitas (X6), dan pelayanan (X7) secara simultan terhadap keputusan berkunjung (Y2) ke Pantai Teluk Asmara.H5: Bahwa ada pengaruh yang signifikan antara keinginan berkunjung (Y1) terhadap keputusan berkunjung (Y2) ke Pantai teluk Asmara. H6: Bahwa ada pengaruh yang signifikan antara daya tarik (X1), branding (X2), image (X3), wom (X4), e-wom (X5), fasilitas (X6), dan pelayanan $(X 7)$ secara parsial terhadap willingnes to recomendation $(Z)$ di Pantai Teluk Asmara. H7: Bahwa ada pengaruh daya tarik (X1), branding (X2), image (X3), wom (X4), e-wom (X5), fasilitas (X6), dan pelayanan (X7) secara simultan terhadap willingnes to recomendation (Z) di Pantai Teluk Asmara. H8: Bahwa ada pengaruh yang signifikan antara keinginan berkunjung $(Y 1)$ terhadap willingness to recommendation $(Z)$ di Pantai Teluk Asmara.. H9: Bahwa ada pengaruh yang signifikan antara keputusan berkunjung (Y2) terhadap willingness to recommendation (Z) di Pantai Teluk Asmara.

\section{METODE PENELITIAN}

Populasi dalam penelitian ini adalah keseluruhan wisatawan yang berkunjung di Pantai Teluk Asmara yang jumlah sangat banyak sehingga diperlukan pengambilan sampel untuk hasil yang akurat. Penelitian ini mengunakan Sampling (pengambilan sampel) dalam pencariaan datanya yaitu dengan non-probability sampling karena jumlah keseluruhan pengunjung yang tak pasti. Dalam penelitian ini menggunakan teknik Accidental Sampling, yaitu teknik penentuan sampel secara aksidental dengan mengambil kasus atau responden yang kebetulan ada atau tersedia di suatu tempat sesuai dengan konteks penelitian (Simamora 2004). Ukuran sampel yang digunakan pada alat analisis SEM Ferdinand (2002) menyatakan bahwa ukuran sampel untuk pengujian model menggunakan SEM adalah antara 100-200 atau tergantung pada jumlah parameter yang digunakan dalam seluruh variabel laten, yaitu jumlah parameter dikalikan 5 sampai 10.

Penelitian ini menggunakan 30 indikator sehingga dengan menggunakan estimasi berdasarkan jumlah parameter diperoleh ukuran sampel sebesar $30 \times 8=240$ responden. Metode pengumpulan data dengan jalan mencatat sebagian kecil dari populasi atau dengan perkataan lain mencatat sampel yang digunakan saja (Supranto, 1997:53). Metode yang digunakan yaitu kuisioner, observasi langsung dan dokumenter.Kuisioner/ angket diberikan kepada para pengunjung yang memenuhi kriteria responden yang telah ditetapkan.

Observasi ini dilakukan untuk memperoleh data mengenai perilaku konsumen dan faktor yang mempengaruhi perilaku konsumen. Observasi dilakukan sebelum kuisioner disebarkan kepada responden. Dengan mencatat dokumen yang dimiliki oleh perusahaan sesuai dengan keperluan penelitian. 
Berdasarkan hipotesis dalam penelitian ini maka metode analisis data yang digunakan adalah analisis SEM (Structural Equation Modeling) dengan menggunakan software WarPls 5.0. Jika dilihat dari penyusunan model serta cara kerjanya, SEM adalah gabungan dari analisis faktor dan analisis regresi yang dapat menjelaskan hubungan antar banyak variabel. Menganalisis model penelitian dengan SEM dapat mengidenfikasi dimensidimensi sebuah konstruk dan pada saat yang sama dapat mengukur pengaruh atau derajat hubungan antar faktor yang telah diidentifikasikan dimensi-dimensinya itu (Ferdinand, 2002:7). Model persamaan struktural (SEM) adalah sekumpulan teknik statistikal yang memungkinkan pengujian sebuah rangkaian hubungan relatif rumit secara simultan.

Beberapa langkah-langkah yang harus diikuti dalam pembuat pemodelan yang lengkap (Ferdinand, 2002:34), yaitu:

1. Pengembangan model secara teoritis

2. Menyusun diagram jalur (path diagram)

3. Mengubah diagram jalur menjadi persamaan struktural

4. Memilih matrik input untuk analisis data

5. Menilai identifikasi model

6. Menilai kriteria Goodness of Fit

7. Interpretasi terhadap model

\section{HASIL ANALISIS DATA}

Model pengukuran dengan reflektif indikator ditentukan berdasarkan korelasi antara item score component yang didestiminasi dengan software WarpPIs 5.0. Validitas konvergen diukur dari korelasi antara skor indikator dengan konstruknya. Indikator individu dianggap valid jika memiliki nilai korelasi diatas $0,7(>0,7)$. Namun menurut loading 0,50 sampai 0,60 masih dapat diterima dengan melihat output korelasi indikator dengan konstruknya (Ghozali, 2008).

Tabel 3

AVE Dan Akar Kuadrat AVE

\begin{tabular}{|c|c|c|}
\hline Variabel & AVE & Akar Kuadrat Ave \\
\hline $\mathrm{X} 1$ & 0,666 & 0,816 \\
\hline $\mathrm{X} 2$ & 0,736 & 0,858 \\
\hline $\mathrm{X} 3$ & 0,695 & 0,833 \\
\hline $\mathrm{X} 4$ & 0,657 & 0,810 \\
\hline $\mathrm{X} 5$ & 0,758 & 0,871 \\
\hline $\mathrm{X} 6$ & 0,707 & 0,841 \\
\hline $\mathrm{X} 7$ & 0,661 & 0,813 \\
\hline $\mathrm{Y} 1$ & 0,812 & 0,901 \\
\hline $\mathrm{Y} 2$ & 0,779 & 0,882 \\
\hline $\mathrm{Z}$ & 0,629 & 0,793 \\
\hline
\end{tabular}

Sumber: Data primer diolah (2018)

Model memiliki validitas diskriminan yang lebih baik apabila akar kuadrat AVE untuk masing-masing konstruk lebih besar dari korelasi antara dua konstruk di dalam model. Menurut Ghozali (2014), AVE yang baik 
disyaratkan memiliki nilai lebih besar dari 0,50. Akar kuadrat AVE dihitung secara manual terlebih dahulu sebelum dilakukan perbandingan. Dalam penelitian ini, nilai AVE dan akar kuadrat AVE untuk masing-masing konstruk disajikan pada Tabel 3:

Tabel 4

Nilai Composite Reliability Dan Cronbach Alpha

\begin{tabular}{|c|c|c|}
\hline Variabel & Composite Reliability & $\begin{array}{c}\text { Cronbach } \\
\text { Alpha }\end{array}$ \\
\hline X 1 & 0,956 & 0,950 \\
\hline X 2 & 0,973 & 0,970 \\
\hline X 3 & 0,953 & 0,945 \\
\hline X 4 & 0,950 & 0,942 \\
\hline X 5 & 0,965 & 0,958 \\
\hline X 6 & 0,956 & 0,947 \\
\hline X 7 & 0,951 & 0,942 \\
\hline Y 1 & 0,979 & 0,977 \\
\hline Y 2 & 0,965 & 0,958 \\
\hline Z & 0,938 & 0,924 \\
\hline
\end{tabular}

Sumber: Data primer diolah (2018)

Dari hasil output WarpPLS pada Tabel 4.63, model menunjukkan nilai composite reliability dan cronbach alpha untuk semua konstruk berada diatas nilai 0,70 . Dengan demikian dapat disimpulkan bahwa semua konstruk memiliki reliabilitas yang baik sesuai dengan batas nilai minimum yang disyaratkan.

Tabel 5

Pengujian Godness Of Fit Full Model Struktural

\begin{tabular}{|c|c|c|c|c|}
\hline No & Godness Of Fit Indeks & Kriteria Fit & Hasil Model & Ket. \\
\hline 1 & $\begin{array}{c}\text { Average path coefficient } \\
(A P C)\end{array}$ & $p<0,05$ & $0,127, P=0,012$ & Baik \\
\hline 2 & $\begin{array}{c}\text { Average } R \text {-squared } \\
\text { (ARS) }\end{array}$ & $p<0,05$ & $0,237, \mathrm{P}<0,001$ & Baik \\
\hline 3 & $\begin{array}{l}\text { Average adjusted } R- \\
\text { square (AARS) }\end{array}$ & $p<0,05$ & $0,211, P<0,001$ & Baik \\
\hline 4 & $\begin{array}{l}\text { Average block VIF } \\
\text { (AVIF) }\end{array}$ & $\begin{array}{c}\text { Acceptable if }<=5, \\
\text { ideally }<=3,3\end{array}$ & $\begin{array}{c}1,092 \\
\text { Acceptable if }<=5, \\
\text { ideally }<=3,3\end{array}$ & Baik \\
\hline 5 & $\begin{array}{c}\text { Average Full collinearity } \\
\text { VIF (AFVIF) }\end{array}$ & $\begin{array}{c}\text { Acceptable if }<=5, \\
\text { ideally }<=3,3\end{array}$ & $\begin{array}{c}1,327 \\
\text { Acceptable if }<=5, \\
\text { ideally }<=3,3\end{array}$ & Baik \\
\hline 6 & Tenenhaus Gof (GOF) & $\begin{array}{l}\text { Small }>=0,1, \text { medium } \\
>=0,25, \text { large }>=0,36\end{array}$ & $\begin{array}{c}0,410 \\
\text { Smal }>=0,1, \text { medium } \\
>=0,25, \text { large }>=0,36\end{array}$ & Baik \\
\hline 7 & $\begin{array}{l}\text { Sympson's paradox } \\
\text { ratio (SPR) }\end{array}$ & $\begin{array}{c}\text { Acceptable if }>=0,7, \\
\text { ideally }=1\end{array}$ & $\begin{array}{c}0,917 \\
\text { Acceptable if }>=0,7 \\
\text { ideally }=1\end{array}$ & Baik \\
\hline 8 & $\begin{array}{c}R \text {-squared contribution } \\
\text { ratio (RSCR) }\end{array}$ & $\begin{array}{c}\text { Acceptable if }>=0,9, \\
\text { ideally }=1\end{array}$ & $\begin{array}{c}0,981 \\
\begin{array}{c}\text { Acceptable if }>=0,9, \\
\text { ideally }=1\end{array}\end{array}$ & Baik \\
\hline 9 & $\begin{array}{c}\text { Statistical suppression } \\
\text { ratio }(S S R)\end{array}$ & Acceptable if $>=0,7$ & $\begin{array}{c}0,958 \\
\text { Acceptable if }>=0,7\end{array}$ & Baik \\
\hline
\end{tabular}


Berdasarkan tabel diatas dapat dijelaskan bahwa Average Path Coefficient $(A P C)$ baik dilihat dari hasil analisis 0,127 dimana jika indeks di bawah 0,05 . Average $R$-squared (ARS) baik dilihat dari hasil analisis 0,237 dengan $P<0,001$ dimana diterima jika indeks di bawah 0,05. Average adjusted $R$-squared (AARS) baik dilihat dari hasil analisis 0,211 dengan $\mathrm{P}$ $<0,001$ dimana diterima jika indeks di bawah 0,05.

Average block VIF (AVIF) baik dari hasil analisis adalah 1,092 dimana diterima jika indeks memenuhi kriteria Acceptable if $<=5$, ideally $<=$ 3,3. Average Full collinearity VIF (AFVIV) baik dari hasil analisis adalah 1,327 dimana diterima jika indeks memenuhi kriteria Acceptable if $<=5$, ideally $<=3,3$.

Tenenhaus Gof (GOF) baik dari hasil analisis 0,410 dimana diterima jika indeks memenuhi kriteria Small $>=0,1$, medium $>=0,25$, large $>=0,36$, dengan demikian secara keseluruhan model dalam penelitian ini dianggap fit karena memiliki nilai GoF > 0,36.

Symspson's paradox ratio (SPR) baik dengan hasil analisis 0,917 diterima jika indeks memenuhi kriteria Acceptable if $>=0,7$, ideally $=1$. $R$ squared contribution ratio ( $R S C R$ ) baik dengan hasil analisis 0,981 diterima jika indeks memenuhi kriteria Acceptable if $>=0,9$, ideally $=1$. Statistical suppression ratio (SSR) baik dengan hasil analisis 0,958 diterima jika indeks memenuhi kriteria Acceptable if $>=0,7$. Nonlinear bivariate causality direction ratio (NLBCDR) baik dengan hasil analisis 0,708 diterima karena memenuhi kriteria Acceptable if $>=0,7$.

Berdasarkan tabel diatas dapat diketahui bahwa kriteria-kriteria dalam uji goodness of fit untuk model struktur diatas secara umum sudah memenuhi kriteria yang dianjurkan atau hasilnya sudah sesuai dengan indeks yang ada.

\section{PEMBAHASAN}

Pengaruh Daya Tarik, Branding, Image, Wom, E-wom, Fasilitas Dan Pelayanan Secara Parsial Terhadap Keinginan Berkunjung Ke Pantai Teluk Asmara

1. Pengaruh daya tarik terhadap keinginan berkunjung ke Pantai Teluk Asmara

Daya tarik wisata terbukti berpengaruh signifikan terhadap keinginan berkunjung wisatawan di Pantai Teluk Asmara. Hasil penelitian ini mendukung penelitian terdahulu yang telah dilakukan oleh Sondakh (2016) yang menemukan bahwa daya tarik wisata obyek wisata secara parsial berpengaruh terhadap minat wisatawan berkunjung ke obyek wisata alam Gunung Mahawu.

Pengaruh positif juga dapat berarti sebaliknya, yaitu semakin menurun kualitas daya tarik wisata akan semakin menurun pula keinginan wisatawan untuk berkunjung ke Pantai Teluk Asmara. 
2. Pengaruh branding terhadap keinginan berkunjung ke Pantai Teluk Asmara

Branding terbukti bepengaruh signifikan terhadap keinginan berkunjung wisatawan di Pantai Teluk Asmara

Pengaruh positif juga dapat berarti sebaliknya, yaitu semakin menurun kualitas branding akan semakin menurun pula keinginan wisatawan untuk berkunjung ke Pantai Teluk Asmara.

3. Pengaruh image/citra terhadap keinginan berkunjung ke Pantai Teluk Asmara

Uji pengaruh X3 (image/citra) dengan $\mathrm{Y} 1$ (keinginan berkunjung) menunjukkan nilai koefisien 0,024 dengan $P$ value 0,36 ini berarti tidak signifikan, karena dikatakan signifikan jika $\mathrm{P}<0,05$, hal ini menunjukkan bahwa image/citra tidak berpengaruh terhadap keinginan berkunjung ke Pantai Teluk Asmara.

4. Pengaruh Wom terhadap keinginan berkunjung ke Pantai Teluk Asmara Uji pengaruh $\mathrm{X} 4$ (Wom) dengan $\mathrm{Y} 1$ (keinginan berkunjung) menunjukkan nilai koefisien $-0,094$ dengan $P$ value 0,070 ini berarti tidak signifikan, karena dikatakan signifikan jika $P<0,05$, hal ini menunjukkan bahwa Wom tidak berpengaruh terhadap keinginan berkunjung ke Pantai Teluk Asmara, bahwa arah hubungan antara X4 terhadap Y1 adalah negatif, jika di interprestasikan berarti "Bahwa Wom tidak mempunyai dampak yang baik untuk meningkatkan keinginan wisatawan untuk berkunjung ke Pantai Teluk Asmara."

5. Pengaruh e-wom terhadap keinginan berkunjung ke Pantai Teluk Asmara

E-wom terbukti berpengaruh signifikan terhadap keinginan berkunjung wisatawan di Pantai Teluk Asmara.

Pengaruh positif juga dapat berarti sebaliknya, yaitu semakin menurun kualitas $E$-wom akan semakin menurun pula keinginan wisatawan untuk berkunjung ke Pantai Teluk Asmara.

6. Pengaruh fasilitas terhadap keinginan berkunjung ke Pantai Teluk Asmara

Fasilitas terbukti berpengaruh signifikan terhadap keinginan berkunjung wisatawan di Pantai Teluk Asmara.

Pengaruh positif juga dapat berarti sebaliknya, yaitu semakin menurun kualitas fasilitas akan semakin menurun pula keinginan wisatawan untuk berkunjung ke Pantai Teluk Asmara

7. Pengaruh pelayanan terhadap keinginan berkunjung ke Pantai Teluk Asmara

Uji pengaruh $\mathrm{X} 7$ (pelayanan) dengan $\mathrm{Y} 1$ (keinginan berkunjung) menunjukkan nilai koefisien $-0,078$ dengan $P$ value 0,111 ini berarti tidak signifikan, karena dikatakan signifikan jika $P<0,05$, hal ini menunjukkan bahwa pelayanan tidak berpengaruh terhadap keinginan berkunjung ke Pantai Teluk Asmara.

Pengaruh Daya Tarik, Branding, Image, Wom, E-wom, Fasilitas Dan Pelayanan Secara Simultan Terhadap Keinginan berkunjung Ke Pantai Teluk Asmara 
Variabel eksogen daya tarik (X1), branding (X2), image/citra (X3), wom (X4), ewom (X5), fasilitas (X6), pelayanan (X7) bersama-sama mempengaruhi variabel keinginan berkunjung ( $Y 1$ ) sebesar 0,179 atau $17,9 \%$. Sedangkan sisanya sebesar $82,1 \%$ lainnya dipengaruhi oleh variabel lain selain ke tujuh variabel eksogen tersebut.

Pengaruh Daya Tarik, Branding, Image, Wom, E-wom, Fasilitas Dan Pelayanan Secara Parsial Terhadap Keputusan Berkunjung Ke Pantai Teluk Asmara

1. Pengaruh daya tarik terhadap keputusan berkunjung ke Pantai Teluk Asmara

Uji pengaruh X1 (daya tarik) dengan Y2 (keputusan berkunjung) menunjukkan nilai koefisien $-0,047$ dengan $P$ value 0,233 ini berarti tidak signifikan, karena dikatakan signifikan jika $\mathrm{P}<0,05$, hal ini menunjukkan bahwa daya tarik tidak berpengaruh terhadap keputusan berkunjung ke Pantai Teluk Asmara.

2. Pengaruh branding terhadap keputusan berkunjung ke Pantai Teluk Asmara

Branding terbukti berpengaruh signifikan terhadap keputusan berkunjung wisatawan di Pantai Teluk Asmara.

Pengaruh positif juga dapat berarti sebaliknya, yaitu semakin menurun kualitas branding akan semakin menurun pula keinginan wisatawan untuk berkunjung ke Pantai Teluk Asmara.

3. Pengaruh image/citra terhadap keputusan berkunjung ke Pantai Teluk Asmara

Uji pengaruh X3 (image/citra) dengan Y2 (keputusan berkunjung) menunjukkan nilai koefisien $-0,098$ dengan $P$ value 0,061 ini berarti tidak signifikan, karena dikatakan signifikan jika $\mathrm{P}<0,05$, hal ini menunjukkan bahwa image/citra tidak berpengaruh terhadap keputusan berkunjung ke Pantai Teluk Asmara.

4. Pengaruh wom terhadap keputusan berkunjung ke Pantai Teluk Asmara

Uji pengaruh X4 (Wom) dengan Y2 (keputusan berkunjung) menunjukkan nilai koefisien $-0,039$ dengan $P$ value 0,270 ini berarti tidak signifikan, karena dikatakan signifikan jika $\mathrm{P}<0,05$, hal ini menunjukkan bahwa wom tidak berpengaruh terhadap keputusan berkunjung ke Pantai Teluk Asmara.

5. Pengaruh e-wom terhadap keputusan berkunjung ke Pantai Teluk Asmara

E-wom terbukti berpengaruh signifikan terhadap keputusan berkunjung wisatawan di Pantai Teluk Asmara.

6. Pengaruh fasilitas terhadap keputusan berkunjung ke Pantai Teluk Asmara

Fasilitas terbukti berpengaruh signifikan terhadap keputusan berkunjung wisatawan di Pantai Teluk Asmara.

Pengaruh positif juga dapat berarti sebaliknya, yaitu semakin menurun kualitas fasilitas akan semakin menurun pula keputusan wisatawan untuk berkunjung ke Pantai Teluk Asmara 
7. Pengaruh pelayanan terhadap keputusan berkunjung ke Pantai Teluk Asmara

Pelayanan terbukti berpengaruh signifikan terhadap keputusan berkunjung wisatawan di Pantai Teluk Asmara.

Pengaruh Daya Tarik, Branding, Image, Wom, E-wom, Fasilitas Dan Pelayanan Secara Simultan Terhadap Keputusan Berkunjung Ke Pantai Teluk Asmara

Variabel eksogen daya tarik (X1), branding (X2), image/citra (X3), wom (X4), e-wom (X5), fasilitas (X6), pelayanan (X7) bersama-sama mempengaruhi variabel keputusan berkunjung (Y2) sebesar 0,085 atau $8,5 \%$. Sedangkan sisanya sebesar $91,5 \%$ lainnya dipengaruhi oleh variabel lain selain ke tujuh variabel eksogen tersebut.

Pengaruh Keinginan Berkunjung Terhadap Keputusan Berkunjung Ke Pantai teluk Asmara

Uji pengaruh $\mathrm{Y} 1$ (keinginan berkunjung) dengan $\mathrm{Y} 2$ (keputusan berkunjung) menunjukkan nilai koefisien $-0,048$ dengan $P$ value 0,229 ini berarti tidak signifikan, karena dikatakan signifikan jika $P<0,05$, hal ini menunjukkan bahwa keinginan berkunjung tidak berpengaruh terhadap keputusan berkunjung ke Pantai Teluk Asmara.

Pengaruh Daya Tarik, Branding, Image, Wom, E-wom, Fasilitas Dan Pelayanan Secara Parsial Terhadap Willingnes to Recommendation di Pantai Teluk Asmara

1) Pengaruh daya tarik terhadap willingnes to recommendation ke Pantai Teluk Asmara

Daya tarik wisata terbukti berpengaruh signifikan terhadap willingnes to recommendation di Pantai Teluk Asmara. Hal ini dapat dibuktikan pada Tabel 5.1 nilai $P$ value 0,010 lebih kecil dari alpha 0,05 pada taraf kepercayaan 95\%. Pengaruh positif juga dapat berarti sebaliknya, yaitu semakin menurun kualitas daya tarik wisata akan semakin menurun pula willingnes to recommendation untuk berkunjung ke Pantai Teluk Asmara.

2) Pengaruh branding terhadap willingnes to recommendation ke Pantai Teluk Asmara

Uji pengaruh X2 (branding) dengan $\mathrm{Z}$ (willingnes to recommendation) menunjukkan nilai koefisien $-0,057$ dengan $P$ value 0,188 ini berarti tidak signifikan, karena dikatakan signifikan jika $P<0,05$, hal ini menunjukkan bahwa branding tidak berpengaruh terhadap willingnes to recommendation ke Pantai Teluk Asmara.

3) Pengaruh image terhadap willingnes to recommendation ke Pantai Teluk Asmara

Uji pengaruh X3 (image/citra) dengan Z (willingnes to recommendation) menunjukkan nilai koefisien 0,103 dengan $P$ value 0,054 ini berarti tidak signifikan, karena dikatakan signifikan jika $P<0,05$, hal ini menunjukkan bahwa image/citra tidak berpengaruh terhadap willingnes to recommendation ke Pantai Teluk Asmara.

4) Pengaruh wom terhadap willingnes to recommendation ke Pantai Teluk Asmara 
Uji pengaruh $\mathrm{X} 4$ (Wom) terhadap $\mathrm{Z}$ (willingnes to recommendation) menunjukkan nilai koefisien $-0,048$ dengan $P$ value 0,226 ini berarti tidak signifikan, karena dikatakan signifikan jika $\mathrm{P}<0,05$, hal ini menunjukkan bahwa Wom tidak berpengaruh terhadap willingnes to recommendation ke Pantai Teluk Asmara.

5) Pengaruh e-wom terhadap willingnes to recommendation ke Pantai Teluk Asmara

E-wom terbukti berpengaruh signifikan terhadap willingnes to recommendation wisatawan di Pantai Teluk Asmara.

Pengaruh positif juga dapat berarti sebaliknya, yaitu semakin menurun kualitas E-wom akan semakin menurun pula willingnes to recommendation untuk berkunjung ke Pantai Teluk Asmara.

6) Pengaruh fasilitas terhadap willingnes to recommendation ke Pantai Teluk Asmara

Fasilitas terbukti berpengaruh signifikan terhadap willingnes to recommendation wisatawan di Pantai Teluk Asmara.

7) Pengaruh pelayanan terhadap willingnes to recommendation ke Pantai Teluk Asmara

Uji pengaruh $X 7$ (pelayanan) dengan $Z$ (willingnes to recommendation) menunjukkan nilai koefisien 0,013 dengan $P$ value 0,418 ini berarti tidak signifikan, karena dikatakan signifikan jika $\mathrm{P}<0,05$, hal ini menunjukkan bahwa pelayanan tidak berpengaruh terhadap willingnes to recommendation ke Pantai Teluk Asmara.

Pengaruh Daya Tarik, Branding, Image, Wom, E-wom, Fasilitas Dan Pelayanan Secara Simultan Terhadap Willingnes to Recommendation di Pantai Teluk Asmara

Variabel eksogen daya tarik (X1), branding (X2), image/citra (X3), wom (X4), e-wom (X5), fasilitas (X6), pelayanan (X7) bersama-sama mempengaruhi variabel Willingness to Recomendation $(Z)$ sebesar 0,367 atau $36,7 \%$. Sedangkan sisanya sebesar $63,3 \%$ lainnya dipengaruhi oleh variabel lain selain ke tujuh variabel eksogen tersebut.

\section{Pengaruh Keinginan Berkunjung Terhadap Willingness to Recommendation di Pantai Teluk Asmara}

Keinginan berkunjung terbukti berpengaruh signifikan terhadap willingnes to recommendation di Pantai Teluk Asmara. Hal ini dapat dibuktikan pada Tabel 5.1 nilai $P$ value 0,030 lebih kecil dari alpha 0,05 pada taraf kepercayaan $95 \%$.

Hasil penelitian ini mendukung penelitian terdahulu yang telah dilakukan oleh Wuryandari (2014) yang menemukan bahwa "Visit Intention berpengaruh signifikan dan paling dominan terhadap Willingness to Recommendation. Nilai original sampel variabel keinginan bekunjung dalam mempengaruhi willingnes to recommendation adalah negatif 0,120 yang menunjukkan bahwa arah hubungan antara $\mathrm{Y} 1$ terhadap $\mathrm{Z}$ adalah negatif, jika di interprestasikan berarti "Semakin menurun keinginan berkunjung semakin menurun pula willingnes to recommendation di Pantai Teluk Asmara", dimana ada beberapa faktor yang mempengaruhi keinginan dari pengunjung diantaranya sikap orang lain dan situasi yang dapat mengubah pendirian dari konsumen tersebut. Rangsangan dari luar dirinya 
yang kemudian diproses dalam diri sesuai dengan karakteristik pribadinya masing-masing.

\section{Pengaruh Keputusan Berkunjung Terhadap Willingness to Recommendation di Pantai Teluk Asmara}

Keputusan berkunjung terbukti berpengaruh tidak signifikan terhadap willingnes to recommendation di Pantai Teluk Asmara.

Nilai original sampel variabel keputusan bekunjung dalam mempengaruhi willingnes to recommendation adalah negatif 0,084 yang menunjukkan bahwa arah hubungan antara Y2 terhadap $\mathrm{Z}$ adalah negatif, jika di interprestasikan berarti "Semakin menurun keputusan berkunjung semakin menurun pula willingnes to recommendation di Pantai Teluk Asmara."

Dalam hal ini willingness to recomendation merupakan perilaku konsumen pasca pembelian/kunjungan. Perilaku ini mungkin mengalami konflik dikarenakan melihat fitur-fitur yang mengkhawatirkan atau mendengar hal-hal yang lebih baik dari tempat wisata lainnya, hal ini dikarenakan perilaku pasca pembelian dipengaruhi oleh bbeberapa faktor diantaranya keyakinan konsumen terhadap produk yang bersangkutan. Hal ini dapat digunakan oleh pengelola untuk lebih memperhatikan hal- halyang menambah keyakinan bagi pengunjung untuk mau merekomendasikan Pantai Teluk Asmara kepada orang lain.

\section{SIMPULAN DAN SARAN}

Berdasarkan hasil analisis Structural Equation Modelling (SEM) dapat diketahui faktor-faktor yang mempengaruhi keinginan dan keputusan berkunjung ke pantai serta implikasinya terhadap willingness to recomendation di Pantai Teluk Asmara maka dapat ditarik beberapa kesimpulan sebagai berikut:

Dalam penelitian ini pengujian secara parsial faktor-faktor yang terdiri atas daya tarik, branding, image, wom, e-wom, fasilitas dan pelayanan yang berpengaruh terhadap keinginan berkunjung ke Pantai Teluk Asmara dilihat dari nilai signifikannya adalah daya tarik wisata, branding, image, e-wom, dan fasilitas, ini berarti bahwa semakin baik daya tarik wisata, branding, image, e-wom dan fasilitas maka akan meningkatkan keinginan wisatawan untuk berkunjung ke Pantai Teluk Asmara. Hal ini dapat dilihat dari hasil penelitin yaitu karakteristik responden berdasarkan usia dan frekuensi kunjungan yang menunjukkan kecenderungan dari wisatawan yang lebih menyukai wisata petualangan dan explore di lokasi baru dengan kecanggihan tekinologi yang digunakan sebagai acuan mencari referensi.

Hasil pengujian secara simultan faktor-faktor yang terdiri atas daya tarik, branding, image, wom, e-wom, fasilitas dan pelayanan yang berpengaruh terhadap keinginan berkunjung ke Pantai Teluk Asmara. Variabel yang paling berpengaruh adalah daya tarik hal ini penting untuk diperhatikan agar kealamian dari objek wisata tetap terjaga sehingga akan semakin meningkatkan keinginan untuk berkunjung bagi wisatawan.

Dalam penelitian ini pengujian secara parsial faktor-faktor yang terdiri atas daya tarik, branding, image, wom, e-wom, fasilitas dan pelayanan yang paling berpengaruh terhadap keputusan berkunjung ke 
Pantai Teluk Asmara dilihat dari nilai signifikannya adalah branding, e-wom, fasilitas dan pelayanan, ini juga berarti jika semakin baik branding, e-wom, fasilitas dan pelayanan maka semakin meningkat pula keputusan wisatwan untuk berkunjung ke Pantai Teluk Asmara. Hal ini dapat dilihat dari hasil penelitian karakteristik responden berdasarkan frekuensi kunjungan yang menunjukan hasil bahwa pengunjung terbanyak adalah kunjungan pertama, ini bisa juga dimaklumi dikarenakan Pantai Teluk Asmara merupakan objek wisata baru yang masih baru dikenal masyarakat sehingga masih diperlukan pengembangan dan perbaikan untuk memenuhi kenginan wisatawan sehingga dapat meningkatkan jumlaah kunjungan wisatanya.

Pengujian secara simultan faktor-faktor yang terdiri atas daya tarik, branding, image, wom, e-wom, fasilitas dan pelayanan yang berpengaruh terhadap keputusan berkunjung ke Pantai Teluk Asmara. Variabel yang paling berpengaruh adalah fasilitas hal ini penting untuk diperhatikan oleh pihak pengelola dimana kelengkapan fasilitas sangatlah penting untuk meningkatkan tingkat keputusan kunjungan wisatawan. Hasil ini sejalan dengan temuan dilapangan dimana pihak pengelola terus melakukan pembangunan guna peningkatan sarana dan prasarana untuk melengkapi dan memperbaiki fasilitas yang ada. Hal ini ditandai dengan adanya kerjasama dengan pihak swasta yang mulai dilakuan dengan pembangunan sarana-sarana pendukung objek wisata.

Hasil uji pengaruh keinginan berkunjung wisatawan terhadap keputusan berkunjung wisatawan di Pantai Teluk Asmara tidak berpengaruh secara signifikan, ini juga berarti jika keinginan berkunjung tidak mempunyai dampak untuk meningkatkan keputusan wisatawan untuk berkunjung. Hal ini dapat dilihat dari hasil penelitian dimana karakteristik responden di usia muda yang menunjukkan kecenderungan dari wisatawan yang lebih menyukai wisata petualangan dan explore.

Dalam penelitian ini pengujian secara parsial faktor-faktor yang terdiri atas daya tarik, branding, image, wom, e-wom, fasilitas dan pelayanan yang paling berpengaruh terhadap willingness to recomendation ke Pantai Teluk Asmara dilihat dari nilai signifikannya adalah daya tarik wisata, e-wom, dan fasilitas, ini juga berarti jika semakin meningkat daya tarik wisata, e-wom, dan fasilitas maka semakin meningkat pula willingness to recomendation ke Pantai Teluk Asmara.

Dari pengujian secara simultan faktor-faktor yang terdiri atas daya tarik, branding, image, wom, e-wom, fasilitas dan pelayanan yang berpengaruh terhadap willingness to recomendation ke Pantai Teluk Asmara. Variabel yang paling berpengaruh yaitu e-wom hal ini penting untuk diperhatikan karena perkembangan jaman yang semakin maju sehingga teknologi memiliki peranan yang sangat penting sebagai sarana promosi guna peningkatan nilai positif. Keterbatasan waktu dalam bersosialisai menjadikan teknologi internet sabagai sarana komunikasi yang dianggap mampu untuk mempermudah segala hal, hal inilah yang dapat digunakan pihak pengelola untuk sarana promosi pengenalan sehingga mampu meningkatkan kesediaan wisatawan untuk merekomendasikan (willingness 
to recomendation) sehingga mampu untuk mpeningkatkan jumlah kunjungan wisatawan.

Hasil uji pengaruh keinginan berkunjung wisatawan terhadap willingness to recomendation ke Pantai Teluk Asmara berpengaruh secara signifikan, dari hasil analisis menunjukkan jika arah hubungan kedua variabel negatif, ini berarti jika semakin menurun keinginan berkunjung maka akan semakin menurun pula willingness to recomendation, dimana ada beberapa faktor yang mempengaruhi keinginan dari pengunjung diantaranya sikap orang lain dan situasi yang dapat mengubah pendirian dari konsumen tersebut. Rangsangan dari luar dirinya yang kemudian diproses dalam diri sesuai dengan karakteristik pribadinya masing-masing.

Hasil uji pengaruh keputusan berkunjung wisatawan terhadap willingness to recomendation ke Pantai Teluk Asmara tidak berpengaruh secara signifikan. Dalam hal ini willingness to recomendation merupakan perilaku konsumen pasca pembelian/kunjungan. Perilaku ini mungkin mengalami konflik dikarenakan melihat fitur-fitur yang mengkhawatirkan atau mendengar hal-hal yang lebih baik dari tempat wisata lainnya, hal ini dikarenakan perilaku pasca pembelian dipengaruhi oleh bbeberapa faktor diantaranya keyakinan konsumen terhadap produk yang bersangkutan. Hal ini dapat digunakan oleh pengelola untuk lebih memperhatikan hal- halyang menambah keyakinan bagi pengunjung untuk mau merekomendasikan Pantai Teluk Asmara kepada orang lain.

\section{DAFTAR PUSTAKA}

Agnelia, Revina Anisa dan Aditya Wardhana. Pengaruh Word Of Mouth Terhadap Minat Beli Konsumen Baraya Travel Pool Buah Batu (Studi Pada Mahasiswa Administrasi Bisnis Universitas Telkom Angkatan 2013). 2016. Jurnal Ekonomi, Bisnis \& Entrepreneurship Vol. 10., No.2, Oktober 2016. ISSN 2443-0633. (Online). Halaman 172-185

Alvionita, Vanny dan Prijati. Pengaruh Word Of Mouth, Citra Merek dan Harga Terhadap Keputusan Pembelian. 2017. Jurnal IImu dan Riset Manajemen Volume 6 Nomer 3 Maret 2017. ISSN: 2461-0593. (Online). Halaman 1

Arikunto, Suharsimi. (2006). Prosedur Penelitian Suatu Pendekatan Praktik, EdRevisi VI. Jakarta: Penerbit PT Rineka Cipta

Damayanti, Mailiza. 2015. Analisis Faktor-Fakktor Yang Mempengaruhi Minat Kunjungan Ulang Pada Objek Wisata Pemandian Air Panas Guci Di Kabupaten Tegal. Skripsi dipublikasikan (Online). Semarang. FAKULTAS EKONOMIKA DAN BISNIS. UNIVERSITAS DIPONEGORO. SEMARANG.

Firdaus, Said dkk. Pengaruh Brand Awareness Dan Brand Image Terhadap Keputusan Pembelian Dan Loyalitas Mahasiswi Yang Berbelanja Online di Kota Banda Aceh. 2015. Jurnal Manajemen Indonesia (JMind) (halaman 69-117) (online)

Ghazali, Imam. 2005. Aplikasi Analisis multivariate dengan SPSS. Semarang: Badan Penerbit UNDIP.

Hasan, Ali dan Niken widiati Setiyaningtiyas. Pengaruh Electronic Word Of Mouth pada Media Sosial Facebook Terhadap Keputusan 
Berkunjung Ke Desa Wisata Nglanggeran Gunungkidul. 2015. Journal Media Wisata Volume 13 Nomer 1 Mei 2015 (Online). (halaman 224-238),

https://dinitriwardani.wordpress.com/2009/03/27/tingkah-laku-konsumenpasca-pembelian-produk-sangat-penting-bagi-perusahaan/ http://journal.uinjkt.ac.id/index.php/esensi (http://pesona.indonesia.travel, 2017). 